\section{Effect of Emulsion Open Therapy of Burns Suo Langciren}

Xi Zhang Shannan People's Hospital, Xi Zhang, PEOPLE'S REPUBLIC OF CHINA

Objective: To evaluate the effects of using the Emulsion Open Therapy of Burns (EOTB).

Methods: From 01 January 1984 to 30 December 1996, our ward has had 71 cases of people who were hospitalized due to sustaining burns, were treated by EOTB. Twenty-three cases in whom the size of the burn wounds were the same, were treated by routine therapy. The ETOB was composed of $60 \mathrm{ml}$ of isotonic saline or distilled water, $20 \mathrm{ml}$ of $70 \#$ petrol, $20 \mathrm{ml}$ of colza oil, $0.5 \mathrm{~g}$ of injectable chlorampheni$\mathrm{col}$, and medicative soap. In a universal sterile container, these materials were mixed until it looked emulsified . After the burn wound was cleaned, the emulsion was put onto the wound, which was left open. This was used for superficial burns (1-2 degree small area) 3-4 times a day, and for deep thickness burns, 4-6 times a day. Most of them did not need skin grafting, as they can heal by themselves. The two groups of patients were compared for the restoration of health, improvement, effectiveness, and mortality.

Results: Sixty-six cases restored health by the use of EOTB, 4 cases were improving, 1 died, and the effectiveness rate was $98.6 \%$. Fifteen cases were restored to health using routine therapy, 3 cases improved, 5 died, and the effectiveness rate was $78.3 \%$. These differences were statistically significant $(p<0.05)$.

Conclusion: We believe that EOTB's curative effect is better than routine therapy. The material was easy to obtain, proved economical, and was easy to administer. We did not identify any toxic actions or side effects. Its use will be applicable in peace or wartime and in cities or villages.

Key words: burns; effectiveness; emulsion; emulsion open therapy; treatment; wounds

Prehosp Disast Med 2001;16(2):s74.

\section{Photo Documentation on the Scene of an Accident: A Complement to the Ordinary Documentation Dr Björn-Ove Suserud}

The Prehospital Research Centre, University College of Borås, Borås, SWEDEN

Introduction: In Sweden, 150 people are injured in traffic every day: seven of them become invalids, and two of them die. Each year, approximately 60,000 people are injured in traffic accidents, and 14,000 of them are so seriously injured that they must be hospitalised.

A traffic accident generates a great deal of energy, which reflects in the types of injuries sustained. Therefore, it is possible to identify characteristic injuries for different kinds of accidents, and with the help of a thorough injuryanamnesis, the physician can be led to the correct diagnosis. To make the assessment of the injuries easier at the accident site, several systems for classification of injuries have been developed to predict the outcome from different injuries.
Personnel in an ambulance service should be able to assess a patient, both primarily and secondarily, when the patient receives prehospital care. This primary assessment on the scene of accident provides the basis for the examination that the physician performs later in the emergency ward.

The type of vehicle involved, impact force, and type of injury are important parameters for a correct evaluation of the patients' condition. The ambulance crew is responsible for the medical information, but they also should inform the physician about the impact force caused by the collision. Visualization with photographs taken at the site could provide additional information that may be helpful for the physician's assessment of the injured patient. The aim of the study was to investigate the advantage of photo documentation at the accident site as a complement to ordinary patient records.

Method: When they arrive on the scene of accident, the ambulance crew from three different ambulance stations, take photographs using a digital camera in a sequence of 3 to 5 pictures according to given instructions. On arrival at the hospital, the pictures are transferred from the camera into a stationary computer for visualisation on a screen and printouts of high quality colour pictures. Thereafter, the pictures are stored with the ordinary patient records. The receiving physician can immediately get information about what the scene of the accident looked like. A first evaluation was made when the physician has answered a questionnaire $(n=25)$ that included both open and closed questions.

Result. An analysis of the first 25 traffic accident cases indicated that $16(64 \%)$ of the receiving physicians thought that the pictures from the scene of the accident were an important aid for them in making a better assessment of the patient's condition. Some of the physicians reported that the pictures in several cases have led to complementary examinations that they did not think would have been done without this documentation from the accident site.

Nine physicians reported that the pictures didn't add anything. In five of the cases, this perception was related to poor quality of the photographs, in two cases the pictures came too late, and in two cases, the patient had died.

Conclusion: Photographs taken at the scene of an accident may be a helpful addition to the routine assessments of victims of traffic accidents.

Key words: ambulances; assessments; crashes; digital cameras; photographs; scene; traffic

E-mail: bjornove.suserud@hb.se Prehosp Disast Med 2001;16(2):s74.

\section{Kegworth: To Know History Is To Predict Future Mr. Hans Svensson \\ Visby, SWEDEN}

Problem: What anatomic injuries will occur within human organ system due to air accident?

Method: Kegworth air accident investigators present an AIS-scored material for all 126 persons involved. By computer-aided analysis, one can record the severity of injuries 